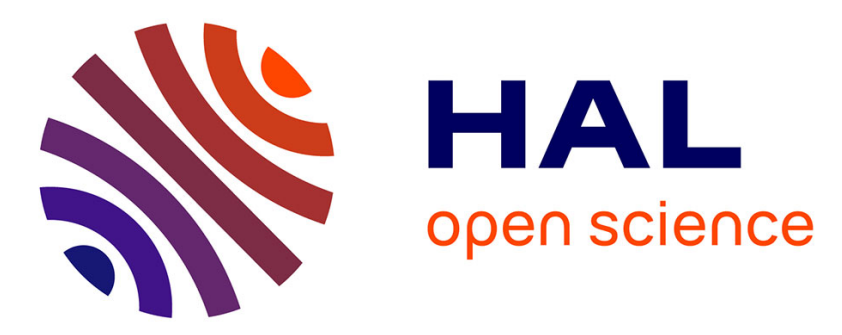

\title{
Culture confirmation of gonococcal infection by recall of subjects found to be positive by nucleic acid amplification tests in general practice
}

\author{
Jens Kjølseth Møller
}

\section{- To cite this version:}

Jens Kjølseth Møller. Culture confirmation of gonococcal infection by recall of subjects found to be positive by nucleic acid amplification tests in general practice. Sexually Transmitted Infections, 2010, 86 (6), pp.478. 10.1136/sti.2010.043703 . hal-00576099

\section{HAL Id: hal-00576099 \\ https://hal.science/hal-00576099}

Submitted on 12 Mar 2011

HAL is a multi-disciplinary open access archive for the deposit and dissemination of scientific research documents, whether they are published or not. The documents may come from teaching and research institutions in France or abroad, or from public or private research centers.
L'archive ouverte pluridisciplinaire HAL, est destinée au dépôt et à la diffusion de documents scientifiques de niveau recherche, publiés ou non, émanant des établissements d'enseignement et de recherche français ou étrangers, des laboratoires publics ou privés. 
1 Culture confirmation of gonococcal infection by recall of subjects found to be positive by

2 nucleic acid amplification tests in general practice

3

$4 \quad$ Jens Kjølseth Møller ${ }^{1,2}$

5

$6 \quad{ }^{1}$ Department of Clinical Microbiology, Lillebælt Hospital, Vejle, Denmark

$7 \quad{ }^{2}$ Department of Clinical Microbiology, Aarhus University Hospital, Skejby, Denmark

8

9 Keywords: NAAT, Neisseria gonorrhoeae, culture, recall samples, general practice

10

11 Revised version

12

13 Correspondence to

14 Dr J.K. Møller, Department of Clinical Microbiology, Institute of Regional Health Services

15 Research, University of Southern Denmark, Lillebælt Hospital, Kabbeltoft 25, DK-7100

16 Vejle, Denmark; jkm@dadlnet.dk

17

18 


\section{Abstract}

20 Objectives: To evaluate a routine notification of general practitioners to recall nucleic acid 21 amplification test (NAAT) positive subjects for culture of Neisseria gonorrhoeae to confirm 22 gonococcal infection in the community.

23 Methods: A retrospective observational study of the routine testing for $N$. gonorrhoeae by analysis of test results compiled from the laboratory information system in two departments of clinical microbiology.

Results: Altogether, 158 male and female subjects with NAAT positive results for $N$. gonorrhoeae were included in the study. Samples for culture of $N$. gonorrhoeae were collected from 102/158 (64.6\%) subjects recalled after a NAAT assay was found positive. Growth of $N$. gonorrhoeae was seen in the samples from 54/102 (52.9\%) of the re-examined NAAT positive subjects. Among subjects with samples collected within the first week after the positive NAAT test, 34/44 (77\%) were confirmed positive by culture.

Conclusion: This study shows that it is possible for the general practitioner to recall a substantial number of NAAT positive subjects to collect swabs for culture of $N$. gonorrhoeae to confirm gonococcal infection in the community. The majority of recall samples is culture positive if collected within a week of the NAAT positive test, and may provide a sufficient monitoring of the drug susceptibility of $N$. gonorrhoeae strains in the community. 
INTRODUCTION: The gold standard of laboratory diagnosis of gonorrhoea has been the culture of the causative agent, Neisseria gonorrhoeae (1). An increasing number of patients in our area are primarily diagnosed with gonorrhoea by a nucleic acid amplification test (NAAT) only. The aim of this study was to evaluate the recall of NAAT positive subjects to collect swabs for culture confirmation of gonococcal infection in the community.

METHODS: A retrospective observational study was performed from March 2009 to March 2010 including all male and female subjects diagnosed by a general practitioner (GP) with a NAAT positive sample for $N$. gonorrhoeae (NG) only. Samples were received and examined in two department of clinical microbiology from their combined catchments area of $1,000,000$ people. The Gen-Probe APTIMA COMBO $2^{\circledR}(\mathrm{AC} 2)$ and the APTIMA ${ }^{\circledR}$ GC (AGC) NAAT assays (Gen-Probe, San Diego, USA) were used. Positive AC2 assays were repeated and furthermore examined with the AGC assay to confirm the initial positive result. The final laboratory report routinely notified the GP that the patient should be re-examined by culture to obtain an antimicrobial susceptibility pattern.

Swabs for culture of NG (charcoal imbibed cotton swab in a Stuart medium) were transported to the laboratory on the same day or mailed by ordinary postal service, and cultured on a chocolate agar plate supplemented with Polymyxin B, Lincomycin, and Amphotericin B at $35^{\circ} \mathrm{C}$ and $10 \% \mathrm{CO}_{2}$ for 48 hours. N. gonorrhoeae was identified by Gram stain and conventional biochemical tests.

The unique Danish civil registry number (CPR) was used to cross link the laboratory results of all samples for NG testing of an individual, and to establish a chronological order of the samples. 
62 RESULTS: A total of 158 subjects, 52 from Vejle and 106 from Aarhus, were included. All

63 initially positive AC2 assays were confirmed by repeat testing and the single analyte assay

64 AGC. Table 1 shows the distribution of female and male samples. Altogether, 102/158 (64.6\%) NAAT positive subjects had swabs collected for culture by a recall examination. A positiv culture of $N$. gonorrhoeae was found in 54/102 (52.9\%). Twenty subjects were not

67 included in the study because they had a culture for $N$. gonorrhoeae collected together with 68 the positive NAAT sample, 16/20 (80\%) were culture positive. Corresponding figures during 69 a two-year period at the clinic of Genito-Urinary Medicine using similar NAAT and culture 70 assays were $40 / 45=89 \%$.

71 Growth of $N$. gonorrhoeae was seen in 34 of 44 (77\%) subjects recalled within the 1st week 72 after their positive NAAT test. Corresponding figures for the 2 nd week, and the 3 rd week or 73 later were $13 / 32(41 \%)$ and $7 / 21(33 \%)$, respectively $\left(\chi^{2}=15.1\right.$, degrees of freedom $=2$, $74 \quad \mathrm{P}<0.001)$.

DISCUSSION:

Recall samples for culture of $N$. gonorrhoeae were collected from two thirds of NAAT positive subjects. Among subjects with samples collected within the first week after the positive NAAT test, three quarters were confirmed positive by culture. The weakness of the retrospective observational design of the present study is the lack of data on antibiotic treatment prior to or after the initial NAAT screening assay, which may preclude the growth of $N$. gonorrhoeae in a recall culture. Furthermore that information was not available to show whether failure to recall was due to subjects not attending or to GPs not routinely requesting culture samples. Culture confirmation of the NAAT positive results is also challenging because of the rapid loss of viability of $N$. gonorrhoeae strains during the transportation of the samples from the community to the laboratory (1). Previous studies also found that about two 
87 thirds of the NAAT results could be confirmed by culture $(2,3)$. However, urgent

88

89

90

91

92

93

94

95

96

97

Word count: Abstract (208), Text (749).

There are no competing interests.

\section{ACKNOWLEDGEMENTS, COMPETING INTERESTS, FUNDING}

The Corresponding Author has the right to grant an exclusive licence (or non exclusive for government employees) on a worldwide basis to the BMJ Publishing Group Ltd to permit this article (if accepted) to be published in STI and any other BMJPGL products and sublicences such use and exploit all subsidiary rights, as set out in our licence http://group.bmj.com/products/journals/instructions-for-authors/licence-forms. 
111 REFERENCES

112 1. Iwen PC, Walker RA, Warren KL, Kelly DM, Linder J, and Hinrichs SH. 1996. Effect

113 of off-site transportation on detection of Neisseria gonorrhoeae in endocervical specimens.

114 Arch. Pathol. Lab. Med. 120:1019-1022.

115 2. Gopal Rao G, Bacon L, Evans J, Dejahang Y, Hardwick R, Michalczyk P, Wong J,

116 and Donaldson A. 2009. Can culture confirmation of gonococcal infection be improved in

117 female subjects found to be positive by nucleic acid amplification tests in community clinics?

118 Sex. Transm. Infect. 85:531-533. doi: 10.1136/sti.2009.036525.

119 3. Rao GG, Bacon L, Evans J, Dejahang Y, Michalczyk P, Donaldson N, and Lewisham

120 Chlamydia and Gonoccoccus Screening Programme. 2008. Prevalence of Neisseria

121 gonorrhoeae infection in young subjects attending community clinics in South London. Sex.

122 Transm. Infect. 84:117-121. doi: 10.1136/sti.2007.026914.

123 


\section{Tables}

126 Table 1. Recall of NAAT positive subjects to collect swabs for culture of N. gonorrhoeae

127

128

129

NAAT positive Swabs for culture

Culture positive

No.

No. $\% \quad(95 \% \mathrm{CI})$

No. $\% \quad(95 \% \mathrm{CI})$

130

$131 \quad$ Female subjects $\quad 69$

$51 \quad 74 \quad(62-83)$

22

$43(30-57)$

132

Urogenital swab ${ }^{\mathrm{a}} \quad 65$

49

21

133 Urine

4

2

1

134

135

Male subjects

89

$51 \quad 57 \quad(47-67)$

32

$63(49-75)$

136 Urine

70

42

28

137 Urethral swab

19

9

4

138

139

${ }^{a}$ Samples from urethra, cervix and vagina

140 